\title{
Characterization of Eagle Ford Solid Bitumen via AFM-IR: Nanoscale Compositional Heterogeneities and the Impact of Thermal Maturity
}

\author{
Aaron M. JubB ${ }^{1, *}$, Justin E. Birdwell ${ }^{2}$, Paul C. \\ HACKLEY $^{1}$, JAVIN J. HATCHERIAN ${ }^{1}$, AND JING QU ${ }^{3}$ \\ ${ }^{1}$ U.S. Geological Survey, Reston, Virginia, United States \\ (*correspondence: ajubb@usgs.gov) \\ ${ }^{2}$ U.S. Geological Survey, Denver, Colorado, United States \\ ${ }^{3}$ University of Delaware, Newark, Delaware, United States
}

Solid bitumen is a petrographically-defined organic matter type produced during petroleum generation and subsequent oil transformation. Solid bitumen is known to impact many reservoir properties including porosity, permeability, and hydrocarbon generation and storage potential. Additionally, solid bitumen reflectance $\left(\mathrm{R}_{\mathrm{o}} \%\right)$ provides an important geothermometer for sedimentary formations with little or no vitrinite. While the molecular composition of solid bitumen will strongly impact these associated parameters (e.g., organic porosity development), analyzing the molecular composition of solid bitumen in situ is challenging.

Here we present work utilizing atomic force microscopybased infrared spectroscopy (AFM-IR) to investigate the in situ molecular composition of solid bitumen within three shale samples from Cenomanian strata of the Upper Cretaceous Eagle Ford Group in southwest Texas. These samples span a natural thermal maturity gradient from the early oil-generation stage to the dry gas window. AFM-IR allows for the rapid collection of thousands of measurements with $\sim 50 \mathrm{~nm}$ resolution from fine $(\leq 20 \mu \mathrm{m})$ solid bitumen macerals within each sample. Our results indicate that Eagle Ford solid bitumen displays both intra- and inter-maceral molecular variation and that with increasing thermal maturity molecular variability decreases. Furthermore, peak ratios derived from aliphatic, aromatic, and carbonyl spectral features indicate that solid bitumen composition between samples (i.e., across thermal maturity stages) is more similar than analysis of bulk kerogen isolates would suggest. These findings provide insight toward understanding the impact of thermal stress on the composition of solid bitumen within the Eagle Ford Group and highlight the growing awareness that organic matter heterogeneity within petroliferous mudrocks extends down to the nanoscale regime. 